\title{
Genomics-Based Marker Discovery and Diagnostic Assay Development for Wheat Blast
}

Michael L. Pieck and Amy Ruck, United States Department of Agriculture-Agricultural Research Service (USDA-ARS), Foreign DiseaseWeed Science Research Unit (FDWSRU); Mark L. Farman, Department of Plant Pathology, University of Kentucky, Lexington 40546; Gary L. Peterson, USDA-ARS, FDWSRU; James P. Stack and Barbara Valent, Department of Plant Pathology, Kansas State University, Throckmorton Plant Sciences Center, Manhattan 66506; and Kerry F. Pedley, USDA-ARS, FDWSRU

\begin{abstract}
Wheat blast has emerged as a major threat to wheat production in South America. Although originally restricted to Brazil, the disease has since been observed in the neighboring countries of Argentina, Bolivia, and Paraguay and recently the pathogen, Magnaporthe oryzae Triticum pathotype, was isolated from infected wheat in Bangladesh. There is growing concern that the pathogen may continue to spread to other parts of the world, including the United States, where several M. oryzae pathotypes are endemic. M. oryzae pathotypes are morphologically indistinguishable and, therefore, must be characterized genotypically. Symptoms of wheat blast include bleaching of the head, which closely resembles the symptoms of Fusarium head blight, further complicating efforts to

monitor for the presence of the pathogen in the field. We used a genomics-based approach to identify molecular markers unique to the Triticum pathotype of $M$. oryzae. One of these markers, MoT3, was selected for the development of a polymerase chain reaction (PCR)-based diagnostic assay that was evaluated for specificity using DNA from 284 M. oryzae isolates collected from a diverse array of host species. Conventional PCR primers were designed to amplify a 361-bp product, and the protocol consistently amplified from as little as $0.1 \mathrm{ng}$ of purified DNA. The specificity of the MoT3-based assay was also evaluated using Fusarium spp. DNA, from which no amplicons were detected.
\end{abstract}

Wheat blast, caused by the fungal pathogen Magnaporthe oryzae B. C. Couch (syn. Pyricularia oryzae Cavara) Triticum pathotype (Couch and Kohn 2002; Murakami et al. 2000; Zhang et al. 2016), has emerged as a serious threat to wheat production in South America. First discovered in the state of Paraná, Brazil in 1985 (Igarashi et al. 1986), the disease has since been reported in all wheatproducing regions of Brazil (Dos Anjos et al. 1996; Goulart and Paiva 2000; Goulart et al. 1990; Igarashi1990; Maciel et al. 2014; Picinini and Fernandes1990) and in the neighboring countries of Argentina (Cabrera and Gutiérrez 2007), Bolivia (Barea and

Corresponding author: K. F. Pedley; E-mail: Kerry.Pedley@ars.usda.gov

This is contribution number 16-261-J from the Kansas Agricultural Experiment Station.

Mention of trade names or commercial products in this publication is solely for the purpose of providing specific information and does not imply recommendation or endorsement by the U.S. Department of Agriculture (USDA).

The USDA prohibits discrimination in all its programs and activities on the basis of race, color, national origin, age, disability, and where applicable, sex, marital status, familial status, parental status, religion, sexual orientation, genetic information, political beliefs, reprisal, or because all or a part of an individual's income is derived from any public assistance program. (Not all prohibited bases apply to all programs.) Persons with disabilities who require alternative means for communication of program information (Braille, large print, audiotape, etc.) should contact USDA's TARGET Center at (202) 720-2600 (voice and TDD). To file a complaint of discrimination write to USDA, Director, Office of Civil Rights, 1400 Independence Avenue, SW, Washington, DC 20250-9410 or call (800) 795-3272 (voice) or (202) 7206382 (TDD). USDA is an equal opportunity provider and employer.

*The $\boldsymbol{e}$-Xtra logo stands for "electronic extra" and indicates that one supplementary figure, one supplementary table, and one supplementary dataset are published online.

Accepted for publication 9 September 2016.

This article is in the public domain and not copyrightable. It may be freely reprinted with customary crediting of the source. The American Phytopathological Society, 2017.
Toledo1996), and Paraguay (Viedma 2005). More recently, wheat blast was reported for the first time outside of South America, during the 2015-16 cropping season in Bangladesh (Malaker et al. 2016). Yield loss attributable to wheat blast is strongly influenced by weather and, under optimal conditions, can reach nearly 100\% (Kohli et al. 2011). Although M. oryzae pathotypes display a high degree of host specificity, isolates of the Triticum pathotype are known to infect other crop species, including black oat, rye, and barley, as well as noncultivated graminaceous species (Anjos and Charchar 2000; Kohli et al. 2011; Mehta and Baier1998; Mehta et al. 2006). Due to the severity and scale of the disease during outbreaks in South America and Bangladesh, there is growing concern that the wheat blast pathogen may continue to spread to other wheat-growing regions throughout the world (Malaker et al. 2016; Valent et al. 2013). Based on the fact that other M. oryzae pathotypes are endemic in these regions, it is believed that $M$. oryzae Triticum strains may be well adapted and, therefore, have the potential to become established.

M. oryzae Triticum isolates can infect all aboveground parts of the plant but head infection is the most prevalent symptom in the field and the one most commonly associated with the disease (Cruz et al. 2015; Igarashi1990; Kohli et al. 2011). When the rachis becomes infected, the portion of the spike above the point of infection becomes bleached. Bleached spikes produce seed that are small or malformed or have low test weight (Urashima et al. 2009), contributing to both yield losses and the spread of the disease via seed transmission. Spike infections also pose a problem from a diagnostic perspective because wheat blast can easily be confused with Fusarium head blight (FHB), which may mask the spread of the pathogen into areas where Fusarium spp. are common (Valent et al. 2013).

Currently, the diagnosis of wheat blast on suspect samples is reliant upon classical disease diagnostic methods, which include visual confirmation of the pyriform M. oryzae conidia. Molecular markers for polymerase chain reaction (PCR)-based assays are limited to confirmation at the species level and cannot be used to determine the pathotype of the isolate (Harmon et al. 2003). This limitation is problematic because opportunistic infection of wheat by endemic $M$. oryzae pathotypes could trigger unnecessary regulatory actions and unneeded mitigation measures by growers. Such an event occurred in 2011, when a single wheat plant displaying wheat blast symptoms 
was discovered in Kentucky and M. oryzae was isolated from the infected head (Farman et al., in press). Although this isolate was later determined to be most closely related to an $M$. oryzae strain isolated from annual ryegrass, it required an intensive effort involving whole-genome sequencing and molecular characterization to rule out the occurrence of an exotic strain of the pathogen (Farman et al., in press).

PCR-based diagnostic assays are now firmly established in the methods employed by plant pathogen diagnostic laboratories and regulatory agencies. Such assays provide a rapid means for the detection of pathogens even when morphological features used for visual diagnoses are not present, such as during early stages of infection. Often, conserved genomic features such as the ribosomal DNA (rDNA) internal transcribed spacer (ITS) regions 1 and 2 are utilized for the production of specific primers (Vincelli and Tisserat 2008). PCR assays based upon the ITS regions are favored because ITS regions 1 and 2 show considerable variation among individual fungal species and can be easily obtained using universal primers that anneal to the conserved portions of the rDNA that flank the ITS regions (White et al. 1990). Additionally, because rDNA is present in multiple copies in most fungal genomes, ITS-based PCR assays are more sensitive than those based on single-copy genes (Vincelli and Tisserat 2008). However, because the ITS regions typically show little variation within a species, they are not suitable for differentiation between pathotypes.

With the advent of new sequencing technologies, it has now become cost-effective to sequence entire genomes of closely related plant pathogens to rapidly obtain targets for diagnostic assay development (Lang et al. 2010). The advantages of this approach are that no a priori knowledge regarding target sites is required and that it allows for the simultaneous development of markers that can then be empirically tested for specificity. In this study, we utilized whole-genome draft sequences of $M$. oryzae strains and a bioinformatic pipeline to identify regions suitable for the development of a PCR-based assay that could differentiate between the $M$. oryzae Triticum strains present in South America from other M. oryzae pathotypes. The objectives of this study were to (i) sequence and assemble the genomes of multiple $M$. oryzae Triticum strains, (ii) perform whole-genome comparisons to identify sequences sufficiently unique to the Triticum pathotype for use as molecular markers, (iii) test a subset of potential makers against a panel of M. oryzae Triticum and Lolium isolates, and (iv) identify a marker for further verification of specificity against a large collection of M. oryzae isolates.

\section{Materials and Methods}

Fungal specimens and plant material. All fungal specimens used in this study are listed in Supplementary Table S1. South American M. oryzae Triticum isolates B2 and P3 and North American Lolium pathotype isolates LpKY97-1, PL3-1, and WBKY11-15 (Farman et al., in press) were used for preliminary screening of M. oryzae Triticum-specific primer pairs. 'Cavalier' wheat (World Wide Wheat L.L.C., Scottsdale, AZ) was used for pathogenicity testing and as the source for wheat genomic DNA.

Pathogen propagation and plant inoculations. Magnaporthe isolates were cultured on oatmeal agar (OMA) plates seeded with dried Whatman filter paper containing mycelia and conidia (Valent et al. 1986). The culture plates were grown under continuous light at room temperature for 7 to 12 days. For DNA extractions, the fungus was allowed to grow on $5-\mathrm{cm}^{2}$ pieces of sterile Whatman filter paper (number 007) placed on the agar surface. For plant inoculations, conidia were harvested in a sterile solution of $0.01 \%$ Tween$20(\mathrm{vol} / \mathrm{vol})$ by gentle agitation with a $1.3-\mathrm{cm}$ flat, soft, nylon paint brush. Conidia suspensions were filtered through a $53-\mu \mathrm{m}$ sieve and the concentration was adjusted to $1 \times 10^{4}$ conidia/ml using a hemocytometer. Newly emerged spikes of wheat (Zadok's growth stage 59) were spray inoculated with an atomizer (Devilbiss Manufacturing Co. Toledo, $\mathrm{OH})$ at $69 \mathrm{Kpa}$ in the United States Department of Agriculture-Agricultural Research Service (USDA-ARS) Foreign Disease-Weed Science Research Unit (FDWSRU) Biological
Safety Level 3 (BSL-3) Plant Pathogen Containment Facility (Melching et al. 1983). Individual heads were covered with a small, clear bag $(7.5$ by $13 \mathrm{~cm})$ with a zipper closure (Uline, Coppell, TX), and placed in a shaded portion of the greenhouse. Bags were removed $24 \mathrm{~h}$ after inoculation and the plants were moved to a greenhouse bench with supplemental high-pressure sodium light to extend the day length to $16 \mathrm{~h}$. Greenhouse temperature was $25^{\circ} \mathrm{C}\left( \pm 4^{\circ} \mathrm{C}\right)$ throughout the experiment. Plants were rated 14 to 16 days after inoculation based on the percentage of observed blasted florets per head. For the purpose of analysis, each individual spike was considered a replication. For liquid culture, a $1-\mathrm{cm}^{2}$ section of OMA culture containing fungal mycelia and conidia was used to inoculate minimal medium ( $3 \mathrm{~g}$ of Casamino acids, $3 \mathrm{~g}$ of yeast extract, and $6 \mathrm{~g}$ of sucrose in 1 liter of $\mathrm{H}_{2} \mathrm{O}$ ) and grown in an incubator at $24^{\circ} \mathrm{C}$ for 7 days.

DNA extraction. For genome sequencing and initial PCR screening, liquid-grown mycelial mats were harvested, blotted dry on paper towels, and lyophilized for $24 \mathrm{~h}$. The lyophilized mycelium was ground to a fine power in liquid nitrogen. For DNA extraction, the lyophilized powder $(200 \mathrm{mg}$ ) was suspended in $4 \mathrm{ml}$ of lysis buffer (50 mM Tris- $\mathrm{HCl}$ [pH 8.0], $50 \mathrm{mM}$ EDTA, [pH 8.0], 0.5 M NaCL, and $1 \%$ sodium dodecyl sulfate) at $65^{\circ} \mathrm{C}$ and ground with a mortar and pestle. Phenol/chloroform/isoamyl alcohol (4 ml, 25:24:1) was added and mixed thoroughly. The mixture was transferred to a $30-\mathrm{ml}$ Corex tube and centrifuged at $8,500 \mathrm{rpm}$ at $4^{\circ} \mathrm{C}$ for $30 \mathrm{~min}$. The aqueous phase was transferred to a clean tube and the DNA was precipitated by adding 0.54 volumes of isopropanol, mixed by inverting, and centrifuged at $8,500 \mathrm{rpm}$ at $4{ }^{\circ} \mathrm{C}$ for $10 \mathrm{~min}$. The pellet was washed with $2 \mathrm{ml}$ of $70 \%$ (vol/vol) ethanol, dried, and resuspended in $0.5 \mathrm{ml}$ of Tris-EDTA (TE) with RNAse A at $100 \mu \mathrm{g} / \mathrm{ml}$. The DNA concentration was quantified using a NanoDrop NO-1000 spectrophotometer (NanoDrop technologies, Wilmington, DE). For additional PCR screening, DNA was extracted directly from Whatman filter paper (Jia et al. 2014). Briefly, a $1-\mathrm{cm}^{2}$ piece of dried filter paper containing fungal structures was placed in a $1.5-\mathrm{ml}$ microcentrifuge tube containing $200 \mu \mathrm{l}$ of $10 \times \mathrm{TE}(100 \mathrm{mM}$ Tris- $\mathrm{HCl}$ and $10 \mathrm{mM}$ EDTA, $\mathrm{pH} 8.0$ ), vortexed briefly, and incubated at $95^{\circ} \mathrm{C}$ for $10 \mathrm{~min}$. Samples were centrifuged for $1 \mathrm{~min}$ at 3,000 rpm and stored at $-20^{\circ} \mathrm{C}$. The DNA solution $(5 \mu \mathrm{l})$ was used as template for PCR analysis. Genomic DNA isolated from Fusarium graminearum strain $\mathrm{PH}-1$ and $F$. oxysporum $\mathrm{f}$. sp. lycopersici strain 4287 was provided by Dr. Corby Kistler, USDA-ARS Cereal Disease Lab, St. Paul, MN.

Genome sequencing and assembly. High-quality genomic DNA $(1 \mu \mathrm{g})$ was fragmented with the Covaris S220 Focused-ultrasonicator (Covaris, Woburn, MA) using the manufacturer's recommended settings to obtain an average DNA fragment length of $500 \mathrm{bp}$, except isolates B2 and B51, which were fragmented to an average length of $300 \mathrm{bp}$. For sample library preparation, the NEBNext DNA Library Prep Master Mix set (New England BioLabs, Beverly, MA) for Illumina (San Diego, CA) and Illumina TruSeq indexed (barcoded) adapters were used according to manufacturer's protocol. The DNA libraries were purified with the QIAquick PCR Purification Kit (Qiagen, Germantown, MD) followed by Agencourt AMPure XP Beads (Beckman Coulter, Danvers, MA) to ensure the removal of adapters and adapter dimers. The Pippin Prep System (Sage Science, Beverly, MA) was used to remove lower molecular weight content and to prepare the 500-bp fragment libraries for longer-read sequencing. The sample libraries were analyzed using the 2100 Bioanalyzer (Agilent Technologies, Santa Clara CA) and quantified with Qubit dsDNA HS Assay Kit (Life Technologies, Carlsbad, CA). The sequencing was performed on the MiSeq personal sequencing system (Illumina) using the 500-cycle MiSeq reagent v2 kit (Illumina) for the 300-bp libraries or the 600-cycle MiSeq reagent v3 kit (Illumina) for the 500-bp libraries, according to the protocol provided.

Genome assembly conducted at USDA-ARS FDWRSU was performed in collaboration with the National Cancer Institute's Advanced Biomedical Computing Center (Ft. Detrick, MD) using CLC Genomics Workbench 7.0.3 (http://www.clcbio.com). Additional 
$M$. oryzae genomic sequences were assembled at the University of Kentucky.

Identification of M. oryzae Triticum-specific loci and primer design. A Perl script was used to split the assembled genomic sequence of M. oryzae Triticum isolate B2 into 500-bp fragments with a 250-bp overlapping sequence (Korf et al. 2003). To identify candidate loci unique to B2, a BLASTN (ver. 2.2.27) (Altschul et al. 1990) search was performed using default parameters to align the segmented B2 genome to a database containing the sequences of 16 non- $M$. oryzae Triticum isolates collected from 10 host species other than wheat (Table 1). B2 sequence fragments without significant similarity to the non-M. oryzae Triticum genomes were used for a second BLASTN search against a database containing three South American M. oryzae Triticum isolates collected from wheat. Sequences without significant similarity were removed. Primers were designed to the remaining sequences using BatchPrimer3 v 1.0 (You et al. 2008).

Conventional PCR. PCR was performed in a $50-\mu$ l reaction containing $1 \times$ ThermoPol buffer (New England BioLabs) $0.2 \mathrm{mM}$ dNTP, $400 \mathrm{~nm}$ each primer (Table 2), $100 \mathrm{ng}$ of template DNA (or $2.5 \mu \mathrm{l}$ of DNA extracted from filter paper or DNA extracted from plant samples), and $5 \mathrm{U}$ of Taq DNA polymerase (New England BioLabs) using a Mastercycler Gradient Thermocycler (Eppendorf AG, Hamburg, Germany) with initial denaturation at $94^{\circ} \mathrm{C}$ for $90 \mathrm{~s}$; followed by 30 cycles of $94^{\circ} \mathrm{C}$ for $30 \mathrm{~s}, 62^{\circ} \mathrm{C}$ for $30 \mathrm{~s}$, and $72^{\circ} \mathrm{C}$ for $60 \mathrm{~s}$; and a final extension at $72^{\circ} \mathrm{C}$ for $2 \mathrm{~min}$. Amplified PCR products were analyzed on $2 \%$ agarose gels and stained with ethidium bromide. Alternatively, amplified PCR products were analyzed using a QIAxcel Advanced System running QIAxcel Screen Gel Software (Qiagen) equipped with a DNA high-resolution cartridge. The OM500 method was used with the following parameters: QX Alignment Marker injection at $4 \mathrm{kV}$ and $20 \mathrm{~s}$, sample injection at
$5 \mathrm{kV}$ for $10 \mathrm{~s}$, and separation at $5 \mathrm{kV}$ for $500 \mathrm{~s}$. A 15 -bp to 1 -kb alignment marker was used and the PCR product size and concentration were determined using a 50- to 800-bp size marker $(50 \mu \mathrm{g} / \mu \mathrm{l})$.

Real-time PCR. Real-time PCR assays were performed on an Applied Biosystems 7500 PCR instrument (Life Technologies). The reaction was performed in a $20-\mu l$ volume containing $1 \mu l$ of template DNA, $10 \mu l$ of TaqMan Universal PCR Master Mix (Life Technologies), $400 \mathrm{nM}$ each primer (Table 2), and $100 \mathrm{nM}$ probe (6'-carboxyflurescein [FAM] at the $5^{\prime}$ end and black hole quencher-1 at the $3^{\prime}$ end) (Eurofins MWG Operon LLC, Huntsville, AL) (Table 2). The real-time PCR assay consisted of $2 \mathrm{~min}$ of incubation at $50^{\circ} \mathrm{C}$ followed by $10 \mathrm{~min}$ of incubation at $95^{\circ} \mathrm{C}$ and 40 cycles at $95^{\circ} \mathrm{C}$ for $15 \mathrm{~s}$ and $60^{\circ} \mathrm{C}$ for $1 \mathrm{~min}$. Data were analyzed using the Applied Biosystems software, version 1.4.0. The threshold cycle $(\mathrm{Ct})$ value was recorded as the cycle at which the fluorescent signal, associated with an exponential amplification of the PCR product, intersected the threshold set at 30 . Every DNA sample was analyzed with triplicate real-time PCR, and three biological replicates were performed for each real-time PCR assay. Average Ct values with calculated standard deviations are reported.

\section{Results}

Using a BLASTN-based computational approach, 78 sequences with a length of $500 \mathrm{bp}$ that were common to all four M. oryzae Triticum isolates but without significant similarity to the other sequenced $M$. oryzae isolates were identified (Supplementary Data $\mathrm{S} 1)$. The genome sequence of $M$. oryzae Triticum isolate B2 was selected as the query genome because it was collected from a recent outbreak of wheat blast in Bolivia and, therefore, was assumed to be representative of current field isolates. To ensure that the markers identified were stable in the Triticum population, sequences from

Table 1. Sequenced Magnaporthe oryzae isolates used in this study

\begin{tabular}{|c|c|c|c|c|c|c|c|}
\hline Isolate & Host $^{\mathbf{a}}$ & Place of isolation & Year & $\begin{array}{l}\text { Collector, source, } \\
\text { or reference }\end{array}$ & $\begin{array}{c}\text { Format of genome } \\
\text { assembly }\end{array}$ & Role $^{\mathbf{b}}$ & Reference \\
\hline PL3-1 & Annual ryegrass & Pulaski Co., KY & 2002 & J. Beale & 454 assembly, paired end & Dev & Farman et al. (in press) \\
\hline P-0028 & Cheat grass & Paraguay & 2014 & M. Kohli & Illumina assembly & Conf & This study \\
\hline P-0029 & Cheat grass & Paraguay & 2014 & M. Kohli & Illumina assembly & Conf & This study \\
\hline DsLIZ & Crabgrass & Lexington, $\mathrm{KY}$ & 2000 & M. Farman & Illumina assembly & Dev & This study \\
\hline PH42 & Finger millet & Philippines & 1991 & D. Tharreau & Illumina assembly & Dev & Farman et al. (in press) \\
\hline B51 & Goosegrass & Quirusillas, Bolivia & 2012 & J. Stack and C. Cruz & Illumina assembly & Dev & This study \\
\hline Arcadia & Green foxtail & Lexington, $\mathrm{KY}$ & 1998 & M. Farman & Illumina assembly & Dev & Farman et al. (in press) \\
\hline CHRF & Perennial ryegrass & Silver Spring, MD & 1996 & P. Dernoeden & Illumina assembly & Dev & This study \\
\hline $\mathrm{CHW}$ & Perennial ryegrass & Severna Park, MD & 1996 & P. Dernoeden & Illumina assembly & Dev & This study \\
\hline $\mathrm{FH}$ & Perennial ryegrass & Fountain Head, MD & 1997 & P. Dernoeden & 454 assembly & Dev & Farman et al. (in press) \\
\hline LpKY97 & Perennial ryegrass & Lexington, $\mathrm{KY}$ & 1997 & P. Dernoeden & 454 assembly, paired end & Dev & Farman et al. (in press) \\
\hline ARB114 (IA1) & Rice & United States & 2009 & Y. Jia & Illumina assembly & Dev & This study \\
\hline ZN61 (IB49) & Rice & United States & 1992 & J. Correll & Illumina assembly & Dev & This study \\
\hline ZN57 (IC17) & Rice & United States & 1992 & J. Correll & Illumina assembly & Dev & This study \\
\hline TM2 (IE1K) & Rice & United States & 2003 & T. Marchetti & Illumina assembly & Dev & This study \\
\hline $70-15$ & Rice & Laboratory cross & 1991 & Chao and Ellingboe 1991 & $\begin{array}{l}\text { Whole-genome shotgun } \\
\text { assembly }\end{array}$ & Dev & Dean et al. 2005 \\
\hline SSFL02 & St. Augustinegrass & Disneyworld, FL & 2002 & M. Farman & Illumina assembly & Dev & This study \\
\hline $\operatorname{Pg} 1213-2$ & Tall fescue & Georgia & 2000 & Tredway et al. 2005 & Illumina assembly & Dev & This study \\
\hline Pg1213-22 & Tall fescue & Georgia & 2000 & Tredway et al. 2005 & Illumina assembly & Dev & This study \\
\hline $\mathrm{B} 2$ & Wheat & Bolivia & 2011 & J. Stack and C. Cruz & Illumina and 454 assemblies & Dev & This study \\
\hline B71 & Wheat & Bolivia & 2011 & J. Stack and C. Cruz & Illumina assembly & Conf & Malaker et al., 2016 \\
\hline $\mathrm{Br} 7$ & Wheat & $\begin{array}{l}\text { Jagupita, Parana, } \\
\text { Brazil }\end{array}$ & 1990 & Zhan et al. 2008 & Illumina assembly & Dev & This study \\
\hline $\mathrm{Br} 80$ & Wheat & Brazil & 1991 & D. Tharreau & Illumina assembly & Dev & This study \\
\hline P3 & Wheat & Canindeyú, Paraguay & 2012 & G. Peterson & Illumina assembly & Conf & This study \\
\hline PY5020 & Wheat & Londrina, Brazil & 2005 & J. M. Fernandes & Illumina assembly & Conf & This study \\
\hline PY22.1 & Wheat & Parana, Brazil & 2007 & J. M. Fernandes & Illumina assembly & Conf & This study \\
\hline $\mathrm{T} 25$ & Wheat & Parana, Brazil & 1988 & S. Iragashi & Illumina assembly & Dev & This study \\
\hline WBKY11-15 & Wheat & Lexington, $\mathrm{KY}$ & 2011 & D. Hershman & 454 assembly, paired end & Dev & Farman et al. (in press) \\
\hline
\end{tabular}

${ }^{\mathrm{a}}$ Annual ryegrass $=$ Lolium multiflorum, Cheat grass $=$ Bromus tectorum, Crabgrass $=$ Digitaria spp. , Finger millet $=$ Eleusine coracana, Goosegrass $=$ E. indica, Green foxtail $=$ Sataria viridis, Perennial ryegrass $=$ L. perenne, Rice $=$ Oryza sativa, St. Augustinegrass $=$ Stenotaphrum secundatum, Tall fescue $=$ Festuca arundinacea , and Wheat $=$ Triticum spp.

${ }^{\mathrm{b}}$ Role in study: Dev $=$ marker development and Conf $=$ marker confirmation . 
archived isolates collected at least 20 years prior were used for comparisons. M. oryzae Triticum B2 candidate sequences that were not present in the draft genome sequences of isolates $\mathrm{Br} 7, \mathrm{Br} 80$, and T25 were removed.

Primer pairs were designed for a subset of the potential markers to test for specificity and validate the computational approach. Genomic DNA obtained from U.S. isolates PL3-1, LpKY97, and WBKY11-15 and South American isolates P3 and B2 was used as the templates for conventional PCR. The Pot 2 transposon is known to be present in isolates of $M$. oryzae from various hosts and has been exploited for population studies and PCR-based diagnostics (Farman 2002; George et al. 1998; Harmon et al. 2003; Kachroo et al. 1994). Primers designed to amplify a region of the Pot 2 transposon were used as a positive control and a 389-bp product was detected for all samples of the test panel (Supplementary Figure S1). For the putative M. oryzae Triticum-specific markers, amplification from one or more of the U.S. isolates was observed for 6 of the 20 primer pairs tested; therefore, these were unsuitable for diagnostic purposes. However, 14 primer sets amplified target sequences exclusively from the South American isolates. Based on this analysis, we selected the MoT3 marker for further evaluation because the MoT3-specific primers produced a single amplicon of the same size for both isolates, and the relative intensity indicated that the sensitivity was greater than the Pot 2 control. This was unexpected, because the MoT3 marker is located within a gene encoding a retinol dehydrogenase and appears to be single copy.

To evaluate the specificity of the MoT3 marker, a collection of 283 $M$. oryzae isolates was tested. These isolates were collected from an array of hosts, with the majority coming from Triticum and Lolium spp. Again, the Pot2a primer set was used as a positive control for all isolates, and all samples tested positive for this marker (Table 3). Amplification of the MoT3 marker was only observed

Table 2. Polymerase chain reaction primers and fluorescent probe used in this study

\begin{tabular}{|c|c|c|c|c|}
\hline Primer, probe & Sequence & Target species & Seq $^{\mathbf{a}}$ & Reference \\
\hline MoT1F & 5'-GCTGTTCTGGGCCACCTAC-3' & Magnaporthe oryzae & WB01 & This study \\
\hline MoT1R & 5'-ATTCCTCCCCGATTTCCTTT-3' & M. oryzae & WB01 & This study \\
\hline MoT2F & 5'-ATCGACGCGAGTACGAAAAC-3' & M. oryzae & WB04 & This study \\
\hline MoT2R & 5'-CATGGGGTGAAAGGACTCAA-3' & M. oryzae & WB04 & This study \\
\hline MoT3F & 5'-GTCGTCATCAACGTGACCAG-3' & M. oryzae & WB12 & This study \\
\hline MoT3R & 5'-ACTTGACCCAAGCCTCGAAT-3' & M. oryzae & WB12 & This study \\
\hline MoT3_1F & 5'- AGGATGTATGCCCTGACTGG-3' & M. oryzae & WB12 & This study \\
\hline MoT3_1R & 5'-CTCGGCGATGCAAAAGTGAA-3' & M. oryzae & WB12 & This study \\
\hline MoT4F & 5'-AGTTGATGGTTCGCATTTGG-3' & M. oryzae & WB05 & This study \\
\hline MoT4R & 5'-AATCGTCCGCACTTTGTCAC-3' & M. oryzae & WB05 & This study \\
\hline MoT5F & 5'-AGAATCCATGCAACGCCCTG-3' & M. oryzae & WB09 & This study \\
\hline MoT5R & 5'AGCAGCCGGTGACTAAGGAT-3' & M. oryzae & WB11 & This study \\
\hline MoT6F & 5'-TGATGGGGTCCGGGAAAAGA-3' & M. oryzae & WB09 & This study \\
\hline MoT6R & 5'-CAGGGCGTTGCATGGATTCT-3' & M. oryzae & WB09 & This study \\
\hline MoT7F & 5'-TTGACTGTACGGGGATCTGC-3' & M. oryzae & WB07 & This study \\
\hline MoT7R & 5'-ACAATTTCCAACCCGTGACA-3' & M. oryzae & WB07 & This study \\
\hline MoT8F & 5'-GATATGGGGCGATGGATTTT-3' & M. oryzae & WB39 & This study \\
\hline MoT8R & 5'-CGACTCGATTTCGACCTTACC-3' & M. oryzae & WB39 & This study \\
\hline MoT9F & 5'-TTCGTGAGGTCGCTTCAAGT-3' & M. oryzae & WB21 & This study \\
\hline MoT9R & 5'-AACGCTAGCGAACCCTTCTC-3' & M. oryzae & WB21 & This study \\
\hline MoT10F & 5'-GTGACAAAGTGCGGACGATT-3' & M. oryzae & WB06 & This study \\
\hline MoT10R & 5'-TGGAAATGTTCGCGTATCCT-3' & M. oryzae & WB06 & This study \\
\hline MoT11F & 5'-ACCAATGTATGCGCGCAGAA-3' & M. oryzae & WB02 & This study \\
\hline MoT11R & 5'-GCCAGATCAACTTCGAGGGC-3' & M. oryzae & WB02 & This study \\
\hline MoT12F & 5'-ATAGCACCGGGAGTTTCGTT-3' & M. oryzae & WB77 & This study \\
\hline MoT12R & 5'-TTGTGCAGAAATTAGCGGAAA-3' & M. oryzae & WB77 & This study \\
\hline MoT13F & 5'-GCCACGAATTTTCGGGTAAT-3' & M. oryzae & WB78 & This study \\
\hline MoT13R & 5'-CCACGCGAAATATTTTGGAA-3' & M. oryzae & WB78 & This study \\
\hline MoT14F & 5'-CAAAATTAGTCGGCGACCTG-3' & M. oryzae & WB08 & This study \\
\hline MoT14R & 5'-CCTCCGGAATCTTCTTGGTC-3' & M. oryzae & WB08 & This study \\
\hline MoT15F & 5'-CAAATTGGCGGACAGAAAGA-3' & M. oryzae & WB45 & This study \\
\hline MoT15R & 5'-CGATATCGTCGAAACCATGC-3' & M. oryzae & WB45 & This study \\
\hline MoT16F & 5'-TCGAAAGAAGGTGGCGAGTA-3' & M. oryzae & WB02 & This study \\
\hline MoT16R & 5'-GCCAAAAATCAGAGCCCAGT-3' & M. oryzae & WB02 & This study \\
\hline MoT17F & 5'-AGGCATTGAGATGGCGTTTA-3' & M. oryzae & WB03 & This study \\
\hline Mot17R & 5'-CGGTTCCTTAGCCAGTAGGG-3' & M. oryzae & WB03 & This study \\
\hline MoT18F & 5'-GATCCGGAACCAACGTGTAA-3' & M. oryzae & WB11 & This study \\
\hline MoT18R & 5'-AAGGATGAACGCAACATTGG-3' & M. oryzae & WB11 & This study \\
\hline MoT19F & 5'-GGTGTTCGCGTTGGATTAAA-3' & M. oryzae & WB18 & This study \\
\hline MoT19R & 5'-GGCCATTTTTCGAAGACACA-3' & M. oryzae & WB18 & This study \\
\hline MoT20F & 5'-CGCAATGGACTGGGAGTTTA-3' & M. oryzae & WB40 & This study \\
\hline MoT20R & 5'-GGCGAATTGAAATGGTTCG-3' & M. oryzae & WB40 & This study \\
\hline Pot2a-L2 & 5'-GCAATTTCATGCAACCGAAA-3' & M. oryzae & $\ldots$ & This study \\
\hline Pot2a-R2 & 5'-CGTACGCCAACCAGATTGAA-3' & M. oryzae & $\ldots$ & This study \\
\hline ITS-Fulf & 5'-ACAACTCATAACCCTGTGAACAT-3' & Fusarium spp. & $\ldots$ & Arif et al. 2012 \\
\hline ITS-Fu1r & 5'-CAGAAGTTGGGTGTTTTACGG-3' & Fusarium spp. & $\ldots$ & Arif et al. 2012 \\
\hline MoT3_FAM2 & $5^{\prime}$-[6FAM]-TTCTAACGGTTTGCAATTGCACAAAACAAC-[BHQ1]-3’b & M. oryzae & WB12 & This study \\
\hline
\end{tabular}

a Target sequence, included as Supplementary Data S1.

${ }^{\mathrm{b}} \mathrm{FAM}=6^{\prime}$-carboxyflurescein and BHQ1 = black hole quencher-1. 
for a single isolate collected from a host other than wheat, and all but one isolate collected from wheat tested positive for MoT3 (Table 3). The wheat-derived isolate that did not test positive for the MoT3 marker was PY05010, and P-0029 was the only isolate not collected from wheat that tested positive. These two isolates were tested for pathogenicity on Cavalier wheat and virulence correlated with the presence of MoT3. Isolate P-0029 was highly virulent, whereas PY05010 was only mildly pathogenic. Genome sequencing of P-0029 confirmed the presence of the MoT3 marker in this isolate, and detected all 77 of the other wheat-specific marker candidates.

To test the sensitivity of the MoT3F and MoT3R primers, a 10-fold serial dilution of $M$. oryzae Triticum genomic DNA was prepared and used as the template in conventional PCR. Using 30 PCR cycles, the MoT3 primers consistently amplified the target sequence in reactions containing as little as $0.1 \mathrm{ng}$ of DNA (Fig. 1A). Because of the greater sensitivity and rapidity offered by real-time PCR (Schaad and Frederick 2002), the MoT3 assay was modified for a Taqman $5^{\prime}$ nuclease assay. Primers MoT3_1F and MotT3_1R were used together with a FAM-labeled probe, Mot3_FAM2 (Table 2). To determine the sensitivity of the assay, the same 10 serial dilutions of genomic $M$. oryzae Triticum DNA template tested by conventional PCR were used; $10 \mathrm{pg}$ of DNA could be detected using real-time PCR (Fig. 1B). Reactions containing $1 \mathrm{pg}$ of template DNA did not yield a positive $\mathrm{Ct}$ value, indicating no amplification of the target sequence. A negative linear relationship was found between the $\mathrm{Ct}$ value and the $\log$ of the diluted $M$. oryzae Triticum DNA $\left(R^{2}=0.995\right)$. Control reactions containing no template DNA did not produce a positive $\mathrm{Ct}$ value through 35 cycles, indicating that no amplification occurred.

$F$. graminearum is a common pathogen of wheat, causing FHB or scab. The symptomology of FHB closely resembles that of wheat blast. As an additional test of specificity, the MoT3 primers were tested to ensure that nonspecific amplification did not occur in the presence of $F$. graminearum DNA. Conventional PCR using $F$. graminearum and $F$. oxysporum genomic DNA did not yield a detectable product with the MoT3F/MoT3R primers (Fig. 2). Integrity of the DNA was demonstrated by the amplification of a portion of the ITS region using primers specific for the genus Fusarium (Arif et al. 2012).

\section{Discussion}

Due to the spread and severity of wheat blast in South America and now Bangladesh, there is growing concern that M. oryzae Triticum strains may spread to other areas of the world (Malaker et al. 2016; Valent et al. 2013). Effective monitoring for such movement will require intensive scouting efforts and a means for rapidly and accurately identifying the pathogen in suspect samples. In the present

Table 3. Magnaporthe oryzae isolates tested for the presence of the MoT3 and Pot2 markers

\begin{tabular}{|c|c|c|c|}
\hline \multirow[b]{2}{*}{ Host species } & \multirow[b]{2}{*}{ Isolates tested } & \multicolumn{2}{|c|}{$\begin{array}{l}\text { Number of isolates } \\
\text { positive for marker }\end{array}$} \\
\hline & & MoT3 & Pot2a \\
\hline Brachiaria spp. & 3 & 0 & 3 \\
\hline Bromus tectorum & 2 & 1 & 2 \\
\hline Digitaria spp. & 30 & 0 & 30 \\
\hline Eleusine spp. ${ }^{\mathrm{a}}$ & 4 & 0 & 4 \\
\hline Eragostis curvula & 1 & 0 & 1 \\
\hline Festuca arundinacea & 11 & 0 & 11 \\
\hline Lolium spp. ${ }^{\mathrm{b}}$ & 72 & 0 & 72 \\
\hline Oryza sativa & 4 & 0 & 4 \\
\hline Setaria $\mathrm{spp}^{\mathrm{c}}$ & 40 & 0 & 40 \\
\hline Stenotaphrum secundum & 3 & 0 & 3 \\
\hline Triticum spp. ${ }^{\mathrm{d}}$ & 115 & 113 & 115 \\
\hline
\end{tabular}

${ }^{a}$ Eleusine spp. includes Eleusine coracana and E. indica.

${ }^{\mathrm{b}}$ Lolium spp. includes Lolium multiflorum, L. perenne, and an unknown Lolium sp.

c Setaria spp. includes Setaria faberi, S. viridis, and unknown Setaria sp.

${ }^{\mathrm{d}}$ Triticum spp. includes Triticum aestivum and T. durum. study, two PCR-based diagnostic assays (end-point PCR and realtime PCR) were developed to detect isolates of the Triticum pathotype of $M$. oryzae using pathogen-specific primers derived from a newly discovered marker, MoT3.

The most important attribute of any diagnostic assay is a high degree of specificity for the target organism. The MoT3 marker was tested using DNA from $284 \mathrm{M}$. oryzae isolates obtained from 11 different host species and collected from widely spaced geographic locations. A deliberate effort was also made to test both archived material and more recently collected isolates to help ensure that the marker was stable in the genome over time. With the exception of two isolates-P-0029 collected from Bromus tectorum that tested positive for MoT3, and PY05010, an isolate from wheat that tested negative-the MoT3 marker was specific for the South American Triticum pathotype.

Unlike obligate biotrophic fungi such as the rusts that are often restricted to a single host species, $M$. oryzae occurs as a series of hostspecialized pathogen populations capable of infecting multiple hosts (Couch et al. 2005). Isolate P-0029 was collected from diseased cheat grass (B. tectorum) growing within a cultivated field of wheat where wheat blast was evident at high levels. Laboratory tests confirmed that isolate P-0029 was virulent on wheat as well as B. tectorum. Additionally, a phylogenetic analysis based on whole-genome sequence data revealed that P-0029 groups with $M$. oryzae strains from wheat (M. Farman, unpublished). Taken together, these data suggest that P-0029 is a bona fide isolate of the Triticum pathotype that was growing on a different host species within a field of M. oryzae Triticuminfected wheat. The opposite appears to be the case for PY05010 because, although it was collected from wheat, it is quite different from the majority of Triticum pathotype isolates. PY05010 was previously characterized using a set of 11 microsatellite (simple-sequence repeat) loci that defined 48 distinct multilocus microsatellite genotypes

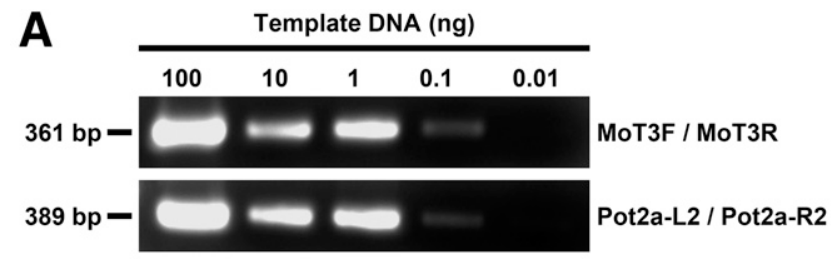

B

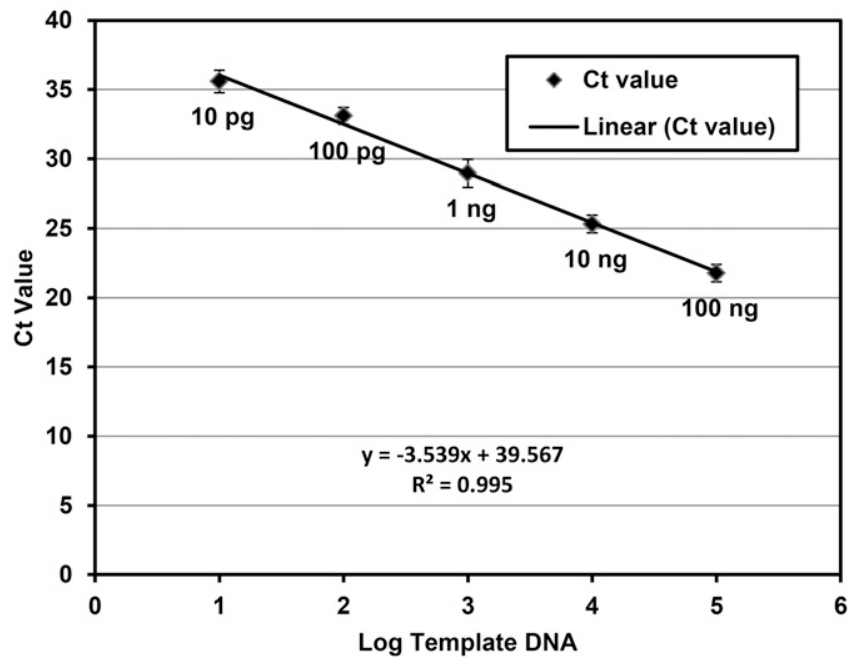

Fig. 1. Sensitivity of conventional polymerase chain reaction (PCR) and real-time PCR assay using diluted template DNA. A, Agarose gel images of conventional PCR assays. The size of the products is indicated to the left of each gel, and the primer combinations (MoT3F/MoT3R or Pot2a-L2/Pot2a-R2) used for each assay are indicated to the right. Amounts of DNA for each reaction are indicated. B, Correlation of the cycle threshold (Ct; number when fluorescence of sample exceeded background fluorescence) values to the log of template DNA concentration using real-time PCR with the Magnaporthe oryzae Triticum pathotype-specific primer set MoT3F/MoT3R and the 6'-carboxyflurescein-labeled probe MoT3_FAM2. 
(MLMG) within a collection of 148 wheat-infecting M. oryzae isolates from Brazil (Maciel et al. 2014). That analysis placed PY05010 in its own unique MLMG (Maciel et al. 2014). More recently, a whole-genome-based phylogenetic analysis revealed that PY05010 belongs to a small subset of wheat blast pathogens that group more closely with isolates of $M$. oryzae obtained from Lolium arundinaceum and L. multiflorum (M. Farman, unpublished data). Thus, although MoT3 appears to be specific for the wheat blast pathogen, it is unable to detect a small fraction of strains from within this population.

Another desirable attribute of a diagnostic assay is a high level of sensitivity. To this end, high-copy-number sequences such as the ITS region of the rDNA are often selected for diagnostic assay development as a convenient way to achieve a desired level of sensitivity. However, although the ITS region is often suitable for distinguishing between different species, it typically lacks the necessary variation for distinguishing intraspecies variation, thus making it unsuitable for wheat blast diagnostics. Likewise, Magnaporthe-specific repetitive elements such as the $M$. oryzae telomeric retrotransposon (MoTeR) and the Pot 2 transposable element do not offer the level of specificity necessary for distinguishing between pathotypes of M. oryzae. Using purified DNA, the detection limit with the MoT3 primers was $0.1 \mathrm{ng}$ with conventional PCR and $10 \mathrm{pg}$ with realtime PCR assays. Although further optimization of the PCR conditions using the MoT3-specific primers to achieve greater levels of sensitivity is possible, it may be necessary to initially screen suspect wheat samples with primers targeting repetitive elements such as MoTeR or Pot 2 to first confirm the presence of M. oryzae. Positive samples could then be rescreened with the more specific MoT3 primers to determine whether they belong to the Triticum pathotype.

The diagnostic assays developed in this study could prove to be valuable resources for combating the spread of the wheat blast pathogen by providing a rapid means for either confirming or ruling out wheat blast in suspect samples. Visual diagnosis of wheat spikes infected by $M$. oryzae is complicated by the fact that the symptoms of the disease resemble those caused by Fusarium spp. (Valent et al. 2013), the causal agent of FHB. Therefore, wheat blast could go unnoticed in areas where FHB is known to occur unless wheat producers and extension specialists are trained to anticipate and recognize the disease. The MoT3 primers were tested against $F$. graminearum and $F$. oxysporum genomic DNA to ensure that nonspecific amplification from Fusarium-infected wheat samples would not interfere with the assay.

Further spread of $M$. oryzae Triticum strains is likely to occur by either wind dispersal of conidia and possibly ascospores, or movement of infected seed. It has been reported that conidia can travel distances of at least 1,000 $\mathrm{m}$ (Urashima et al. 2007); thus, although wind dispersal is a concern for further spread in South America and South Asia, it is unlikely that wind alone will greatly contribute to the dissemination of the pathogen to other parts of the world. Therefore, man-mediated movement of infected seed remains the primary concern. Seed transmission of wheat blast has been established (Goulart and Paiva 2000; Maciel et al. 2014). One study determined that the

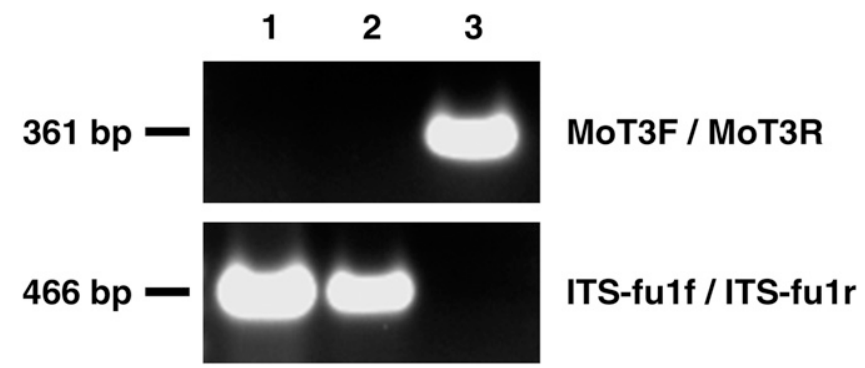

Fig. 2. Agarose gels of polymerase chain reaction (PCR) assays showing the specificity of the primers. The size of the products is indicated to the left of each gel, and the primer combinations (MoT3F/MoT3R or ITS-fu1f/ITS-fu1r) used for each assay are indicated to the right. Genomic DNA for each assay is indicated by lane number: 1 = Fusarium graminearum, 2 = F. oxysporum, and $3=$ Magnaporthe oryzae Triticum pathotype isolate B2. percentage of infected seed from fields where the disease was present reached levels as high as $83 \%$ (Urashima et al. 2009). The assay presented here could be used for testing seed for the presence of possible inoculum and could help prevent the spread of wheat blast into new areas. For local movement, the assay could be used in spore trap experiments for in-field disease monitoring and epidemiology studies. The MoT3-based assay could also be used to provide a rapid means for determining whether wheat blast discovered in new areas is caused by endemic or exotic isolates. The MoT3 marker was not detected in any of the North American M. oryzae isolates examined and, therefore, could be used to assist in determining the origin of M. oryzae isolates infecting wheat if the disease were to occur in the United States.

Because it is now known that some endemic strains of $M$. oryzae in the United States have the capacity to infect wheat under the appropriate conditions, it is imperative that a method for rapid determination of pathogen origin is available for future discoveries, because this information will affect how researchers and regulatory agencies respond. Likewise, because importation of the pathogen on infected seed is the most likely way for the disease to spread, surveillance of grain from infected areas is warranted. The MoT3-based PCR assays presented here have the demonstrated specificity to differentiate the Triticum pathotype from other $M$. oryzae pathotype populations and could prove useful for monitoring shipments of seed. However, further work to determine the appropriate sampling methods to assist in these control measures will be required.

\section{Acknowledgments}

This project is supported by Agriculture and Food Research Initiative Competitive Grant number 2013-68004-20378 from the USDA National Institute of Food and Agriculture and by the USDA-ARS Project number 8044-22000-041-00. M. L. Pieck was supported, in part, by a USDA-ARS postdoctoral fellowship awarded to K. F. Pedley. Isolates of M. oryzae collected in Brazil were kindly provided by J. L. Nunes Maciel under the terms of a material transfer agreement between Empresa Brasileira de Pesquisa Agropecuária (EMBRAPA) and the USDA-ARS. We thank A. Akhunova at the Kansas State University Integrated Genomic Facility, J. Shan at the Frederick National Laboratory for Cancer Research, and J. Lehr at the USDA-ARS FDWSRU for their contributions to this work.

\section{Literature Cited}

Altschul, S. F., Gish, W., Miller, W., Myers, E. W., and Lipman, D. J. 1990. Basic local alignment search tool. J. Mol. Biol. 215:403-410.

Anjos, J. R. N., and Charchar, M. J. A. 2000. Natural infection of barley by Pyricularia grisea in Brazil. Fitopatol. Bras. 25:205-208.

Arif, M., Chawla, S., Zaidi, N. W., Rayar, J. K., Variar, M., and Singh, U. S. 2012 Development of specific primers for genus Fusarium and $F$. solani using rDNA sub-unit and transcription elongation factor (TEF-1 $\alpha$ ) gene. Afr. J. Biotechnol. 11:444-447.

Barea, G., and Toledo, J. 1996. Identificación y zonificación de Pyricularia o brusone (Pyricularia oryzae) en el cutivo de trigo en el departamento de Santa Cruz. Centro de Inestigación Agrícola Tropical. Informe Tecnico. Proyecto de Investigacion Trigo, Santa Cruz de la Sierra, Bolivia.

Cabrera, M. G., and Gutiérrez, S. 2007. Primer registro de Pyricularia grisea en cultivos de trigo del NE de Argentina. Depto. Protección Vegetal, Facultad de Ciencias Agrarias, Universidad Nacional del Nordeste. Available online at: http://www.agr.unne.edu.ar/images/documentos/extension/Res2007/ SanVegetal/SanVegetal_06.pdf

Chao, C.-C. T., and Ellingboe, A. H. 1991. Selection for mating competence in Magnaporthe grisea pathogenic to rice. Can. J. Bot. 69:2130-2134

Couch, B. C., Fudal, I., Lebrun, M. H., Tharreau, D., Valent, B., van Kim, P., Notteghem, J. L., and Kohn, L. M. 2005. Origins of host-specific populations of the blast pathogen Magnaporthe oryzae in crop domestication with subsequent expansion of pandemic clones on rice and weeds of rice. Genetics 170:613-630.

Couch, B. C., and Kohn, L. M. 2002. A multilocus gene genealogy concordant with host preference indicates segregation of a new species, Magnaporthe oryzae, from M. grisea. Mycologia 94:683-693.

Cruz, C. D., Kiyuna, J., Bockus, W. W., Todd, T. C., Stack, J. P., and Valent, B. 2015. Magnaporthe oryzae conidia on basal wheat leaves as a potential source of wheat blast inoculum. Plant Pathol. 64:1491-1498.

Dean, R. A., Talbot, N. J., Ebbole, D. J., Farman, M. L., Mitchell, T. K., Orbach, M. J., Thon, M., Kulkarni, R., Xu, J. R., Pan, H., Read, N. D., Lee, Y.-H., Carbone, I., Brown, D., Oh, Y. Y., Donofrio, N., Jeong, J. S., Soanes, D. M., Djonovic, S., Kolomiets, E., Rehmeyer, C., Li, W., Harding, M., Kim, S., Lebrun, M.-H., Bohnert, H., Couglan, S., Butler, J., Clavo, S., Ma, L.-J., Nicol, R., Purcell, S., Nusbaum, C., Galagan, J. E., and Birren, B. W. 2005 The genome sequence of the rice blast fungus Magnaporthe grisea. Nature 434:980-986. 
Dos Anjos, J., Da Silva, D., Charchar, M., and Rodrigues, G. 1996. Ocorrência de brusone (Pyricularia grisea) em trigo e centeio na região dos cerrados do Brasil Central. Pesqui. Agropecu. Bras. 31:79-82.

Farman, M. L. 2002. Pyricularia grisea isolates causing gray leaf spot on perennial ryegrass (Lolium perenne) in the United States: Relationship to P. grisea isolates from other host plants. Phytopathology 92:245-254.

Farman, M., Peterson, G., Chen, L., Starnes, J., Valent, B., Bachi, P., Murdock, L., Hershman, D., Pedley, K., Fernandes, J. M., and Bavaresco, J. 2017. The Lolium pathotype of Magnaporthe oryzae recovered from a single blasted wheat plant in the United States. Plant Dis. (in press). doi:10.1094/PDIS-05-16-0700-RE

George, M. L. C., Nelson, R. J., Zeigler, R. S., and Leung, H. 1998. Rapid population analysis of Magnaporthe grisea by using rep-PCR and endogenous repetitive DNA sequences. Phytopathology 88:223-229.

Goulart, A., and Paiva, F. 2000. Perdas no rendimiento de grãos de trigo causada por Pyricularia grisea, nos anos de 1991 e 1992, no Mato Grosso do Sul. Summa Phytopathol. 26:279-282.

Goulart, A., Paiva, F., and Mesquita, A. 1990. Ocorrência da brusone (Pyricularia oyyzae) do trigo (Triticum aestivum) em Matto Grosso do Sul. Fitopatol. Bras. 15:112-114.

Harmon, P. F., Dunkle, L. D., and Latin, R. 2003. A rapid PCR-base method for the detection of Magnaporthe oryzae from infected perennial ryegrass. Plant Dis. 87:1072-1076

Igarashi, S. 1990. Update on wheat blast (Pyricularia oryzae) in Brazil. Pages 480-483 in Proc. Int. Conf. Wheat Nontrad. Warm Areas. D. Saunders, ed. CIMMYT, México DF, Mexico.

Igarashi, S., Utiamada, C. M., Igarashi, L. C., Kazuma, A. H., and Lopes, R. S. 1986. Ocorrência de Pyricularia sp. no estado do Paraná. Fitopatol. Bras. 11:351-352.

Jia, Y., Wamishe, Y. A., and Zhou, B. 2014. An expedited method for isolation of DNA for PCR from Magnaporthe oryzae stored on filter paper. Crop J. 2:267-271.

Kachroo, P., Leong, S. A., and Chattoo, B. B. 1994. Pot2, an inverted repeat transposon from the rice blast fungus Magnaporthe grisea. Mol. Gen. Genet. 245:339-348.

Kohli, M. M., Mehta, Y. R., Guzman, E., De Viedma, L., and Cubilla, L. E. 2011. Pyricularia blast - a threat to wheat cultivation. Czech J. Genet. Plant 47: S130-S134.

Korf, I., Yandell, M., and Bedell, J. 2003. Blast. O'Reilly Media, Sebastopol, CA.

Lang, J. M., Hamilton, J. P., Diaz, M. G. Q., Van Sluys, M. A., Burgos, M. R. G., Cruz, C. M. V., Buell, C. R., Tisserat, N. A., and Leach, J. E. 2010. Genomicsbased diagnostic marker development for Xanthomonas oryzae pv. oryzae and X. oryzae pv. oryzicola. Plant Dis. 94:311-319.

Maciel, J. L. N., Ceresini, P. C., Castroagudin, V. L., Zala, M., Kema, G. H. J., and McDonald, B. A. 2014. Population structure and pathotype diversity of the wheat blast pathogen Magnaporthe oryzae 25 years after its emergence in Brazil. Phytopathology 104:95-107.

Malaker, P. K., Barma, N. C. D., Tiwari, T. P., Collis, W. J., Duveiller, E., Singh, P. K., Joshi, A. K., Singh, R. P., Braun, H.-J., Peterson, G. L., Pedley, K. F., Farman, M. L., and Valent, B. 2016. First report of wheat blast caused by Magnaporthe oryzae pathotype Triticum in Bangladesh. Plant Dis. 100:2330.

Mehta, Y. R., and Baier, A. 1998. Variação patogênica entre isolados de Magnaporthe grisea atacando triticale e trigo no estado do Paraná. Summa Phytopathol. 24: $119-125$
Mehta, Y. R., Nunes, M. P., and Oliveira, J. C. 2006. Occurrência de brusone em aveia no Estado do Paraná. Pages 55-57 in: Resultados Experimentais. XXVI Reunião da Comissão Brasileira de Pesquisa de Aveia, Guarapuava, Paraná, Brazil.

Melching, J. S., Bromfield, K. R., and Kingsolver, C. H. 1983. The plant pathogen containment facility at Frederick, Maryland. Plant Dis. 67:717-722.

Murakami, J., Tosa, Y., Kataoka, T., Tomita, R., Kawasaki, J., Chuma, I., Sesumi, Y., Kusaba, M., Nakayashiki, H., and Mayama, S. 2000. Analysis of host species specificity of Magnaporthe grisea toward wheat using a genetic cross between isolates from wheat and foxtail millet. Phytopathology 90:1060-1067.

Picinini, E., and Fernandes, J. 1990. Ocorrência da brusone (Pyricularia oryzae) em lavouras comerciais de trigo (Triticum aestuvum) no Estado do Rio Grande do Sul. Fitopatol. Bras. 15:83-84.

Schaad, N. W., and Frederick, R. D. 2002. Real-time PCR and its application for rapid plant disease diagnostics. Can. J. Plant Pathol. 24:250-258.

Tredway, L. P., Stevenson, K. L., and Burpee, L. L. 2005. Genetic structure of Magnaporthe grisea populations associated with St. Augustinegrass and tall fescue in Georgia. Phytopathology 95:463-471.

Urashima, A. S., Grosso, C. R. F., Stabili, A., and Merola Bottan, J. H. 2009. Effect of Magnaporthe oryzae on seed germination, yield and quality of wheat. Pages 267-277 in: Advances in Genetics, Genomics and Control of Rice Blast Disease. G.-L. Wang and B. Valent, eds. Springer Science and Business Media, New York.

Urashima, A. S., Leite, S. F., and Galbieri, R. 2007. Eficiência da disseminação aérea em Pyricularia grisea. Summa Phytopathol. 33:275-279.

Valent, B., Bockus, W., Cruz, C., Stack, J., Farman, M., Hershman, D., Paul, P., Peterson, G., Pedley, K., and Magarey, R. 2013. Recovery plan for wheat blast caused by Magnaporthe oryzae Triticum pathotype. Online publication. USDA National Plant Disease Recovery System. https://www.ars.usda.gov/ARSUserFiles/00000000/ opmp/Wheat\%20Blast\%20Recovery\%20Plan\%20Final.pdf

Valent, B., Crawford, M. S., Weaver, C. G., and Chumley, F. G. 1986. Genetic studies of fertility and pathogenicity in Magnaporthe grisea (Pyricularia oryzae). Iowa State J. Res. 60:569-594.

Viedma, L. 2005. Wheat blast occurrence in Paraguay. (Abstr.) Phytopathology 95:S152.

Vincelli, P., and Tisserat, N. 2008. Nucleic acid-based pathogen detection in applied plant pathology. Plant Dis. 92:660-669.

White, T. J., Bruns, T., Lee, S., and Taylor, J. W. 1990. Amplification and direct sequencing of fungal ribosomal RNA genes for phylogenetics. Pages 315-322 in: PCR Protocols: A Guide to Methods and Applications. M. A. Innis, D. H. Gelgard, J. J. Sninsky, and T. J. White, eds. Academic Press, New York.

You, F. M., Huo, N., Gu, Y. Q., Luo, M. C., Ma, Y., Hane, D., Lazo, G. R., Dvorak, J., and Anderson, O. D. 2008. BatchPrimer3: A high throughput web application for PCR and sequencing primer design. BMC Bioinf. 9:253.

Zhan, S. W., Mayama, S., and Tosa, Y. 2008. Identification of two genes for resistance to Triticum isolates of Magnaporthe oryzae in wheat. Genome 51: 216-221.

Zhang, N., Luo, J., Rossman, A. Y., Aoki, T., Chuma, I., Crous, P. W., Dean, R., de Vries, R. P., Donofrio, N., Hyde, K. D., Lebrun, M.-H., Talbot, N. J., Tharreau, D., Tosa, Y., Valent, B., Wang, Z., and Xu, J.-R. 2016. Generic names in Magnaporthales. IMA Fungus 7:155-159. 